\title{
Aportaciones de la toponimia a la investigación de la historia del léxico hispánico
}

\author{
Stefan Ruhstaller \\ Universidad Pablo de Olavide, Sevilla \\ sruhkuh@upo.es
}

\begin{abstract}
Resumen: En la toponimia se conserva, de forma fosilizada, abundante información léxica que puede ser aprovechada para complementar la documentación histórica que ofrece la lengua viva reflejada en los textos. Los aspectos de la historia del léxico que pueden ser investigados gracias al estudio toponímico son diversos: detalles cronológicos de la evolución, la existencia de variantes fonéticas y de derivados, cambios en la difusión geográfica, entre otros; a veces incluso se atestiguan a través de los nombres formas nunca documentadas como apelativos. Para poner de relieve el procedimiento de análisis en que debe basarse este tipo de investigación estudiaremos una serie de casos concretos de formas toponímicas basadas en el castellano, destacando (no sin advertir de las dificultades que encierra el tema) la aportación del material examinado a la lexicología histórica y la etimología de esta lengua.
\end{abstract}

Palabras clave: Lexicología histórica; etimología; lexicografía; léxico castellano.

\begin{abstract}
Place names contain, in fossilized form, abundant lexical information that can be used to supplement the historical record of the living language reflected in texts. By studying place names specific aspects of the history of lexicon can be investigated, such as chronological details of the historical development of words, the existence of phonetic variants and derivatives, changes in the geographic distribution, among others. Sometimes proper names even attest lexical items never documented as common nouns. In order to explain the principles on which this research should be based we will study a number of cases of place names based on Castilian, highlighting (not without warning of the difficulties involved in the subject) the contribution of the material examined to the history of Spanish lexicon and to etymology.
\end{abstract}

Keywords: Historical lexicology; etymology; lexicography; Spanish lexicon.

》) Ruhstaller, Stefan. 2015. "Aportaciones de la toponimia a la investigación de la historia del léxico hispánico”. Quaderns de Filologia: Estudis Lingüístics XX: 89-109. doi: 10.7203/qfilologia.20.7514 

1. El valor de la contribución que la investigación toponimíca es capaz de hacer a la lexicología histórica es bien conocido. En trabajos como los de Rohlfs 1951, Ruhstaller / Gordón 1993 o Ruhstaller 1995 se ponen de relieve distintos tipos de información (documentaciones tempranas, variantes fonéticas, derivados no atestiguados como apelativos, puntualizaciones semánticas, delimitación de áreas de difusión geográfica) que proporciona el análisis lingüístico de los nombres de lugar, y se presentan numerosos ejemplos concretos que demuestran la eficacia del método de estudio propuesto. Por otra parte, en una obra lexicográfica tan importante como el Diccionario crítico etimológico castellano e hispánico se recurre con frecuencia, como se comprueba inmediatamente al repasar el extenso índice de voces contenido en el sexto tomo, a los materiales toponímicos para suplir la falta de testimonios de otra naturaleza (Ruhstaller 2010: 133-135); si en el diccionario etimológico el aprovechamiento de los nombres de lugar no es sistemático ello se debe sin duda al escaso número de estudios toponomásticos realmente fiables, y orientados no solo a la interpretación del origen de cada nombre a partir de un interés localista sino en mucha mayor medida a la lexicología, la dialectología y la historia de la lengua, de que disponían los autores en su momento.

Para mostrar cómo puede explotarse el potencial que contiene la toponimia como instrumento al servicio de la lexicología histórica y la etimología vamos a presentar a continuación una serie de casos concretos. Como se verá, la aportación del estudio toponomástico tiene carácter generalmente complementario, pues los datos toponímicos a menudo reflejan hechos lingüísticos puntuales de épocas pasadas de las que no queda rastro en los textos, si bien, ocasionalmente, los nombres de lugar constituyen el único testimonio de la existencia de voces, como veremos. Con esta presentación de una serie de casos concretos quiero animar a que la metodología aquí propuesta se aplique sistemáticamente a futuros estudios de lexicología histórica y etimología; el beneficio para esta rama de la investigación lingüística puede ser notable, pues la información que encierran los nombres de lugar -a condición de que se interpreten adecuadamente- es enorme.

2. Un primer ejemplo que vamos a ver es el de la voz villar. Evidentemente, este derivado de villa no ofrece muchas dificultades desde el punto de vista de su explicación etimológica, por lo que en el $D C E C H$ 
(s.v. villa) no se le dedican más que cinco líneas, en las que se señala que el vocablo está recogido en el Diccionario de autoridades, que procede del "b. lat. VİLLARIS "población'”, y que es "en realidad solo conocido como nombre de lugar o de persona", como Villar del Arzobispo y numerosos "ejs. arcaicos SS. X-XIII, que al menos en parte son nombres propios, en Oelschl[äger]": Con la alusión de Corominas al escasísimo uso de villar como apelativo contrasta la información que ofrece al respecto el diccionario académico, que define la voz como 'pueblo pequeño', sin restringir su uso ni diatópica ni diacrónicamente. Este hecho resulta sorprendente, puesto que en la lengua actual villar evidentemente no goza de un uso ilimitado. A esto se suma que en el Diccionario de autoridades la propia Academia no ofrecía ni un solo testimonio que acreditara el uso, ni tampoco siquiera una definición propiamente dicha, ya que en lugar de esta se remitía al artículo village 'población corta, y abierta' ${ }^{1}$, galicismo para el que se aducían dos autoridades del siglo XVII, referentes, como destaca el $D C E C H$, a Navarra y a Flandes, respectivamente.

Resulta interesante ampliar esta escueta y un tanto contradictoria información que ofrecen los diccionarios, así como puntualizar algunos aspectos, especialmente el semántico, partiendo de información complementaria de naturaleza al menos en parte toponímica. En prácticamente todo el dominio peninsular del español nos encontramos con nombres de lugar que contienen la voz villar, y ello en gran número: tan solo en Navarra se contabilizan una veintena de casos, y en Andalucía más de trescientos, según los respectivos buscadores toponímicos. Una fuente medieval como el Libro de la montería (de mediados del s. XIV) contiene más de veinte ejemplos de El Villar, algunos con complementos como de Assensio, de Frades, de las Nogeras, de Ferreria, otros integrados en formaciones como Naual Villar, La Muela del Villar, La Sierra del Villar, El Colmenar del Villar, etc. (Ruhstaller 1995: 202). Es llamativo que buena parte de estos nombres sean derivados mediante sufijos diminutivos: hallamos El Villarejo en $\mathrm{Av}, \mathrm{Ca}, \mathrm{Co}, \mathrm{Gr}, \mathrm{Gu}, \mathrm{J}$, Se,

\footnotetext{
${ }^{1}$ Esta definición parece estar inspirada al menos parcialmente en una de las dos autoridades citadas: "Moch es un Village abierto, y no dista mas de quatro leguas del Vaál". Para la influencia de las autoridades en las definiciones del primer diccionario académico véase Ruhstaller, 2000: 206-207.
} 
Te, To y Z (en esta última provincia nada menos que siete casos) ${ }^{2}, L o s$ Villarejos en Gr, Gu, J y To, Cerro de Villarejos en Se, El Villarico en J, e incluso una forma doblemente sufijada El Villarejillo en J, y ya en el Libro de la montería se documentan El Villareio de Domingo Martin, El Colladiello del Villareio, La Cabeça de Villareio, así como dos El Villareio, que completan los testimonios medievales a los que alude el $D C E C H$. Tampoco falta algún que otro derivado con valor aumentativo, como El Villarón $\mathrm{Ba}, \mathrm{Hu}, \mathrm{Na}$ o Los Villarones $\mathrm{Co}$, $\mathrm{Hu}$. Una formación como Villarosa Gr, por otra parte, parece describir, con su sufijo colectivo $^{3}$, un lugar donde existen varios referentes clasificables como 'villares'4.

Para determinar el significado exacto de villar en la lengua medieval son interesantes también los nombres que combinan la voz con ciertos complementos: topónimos como Villar Grande Se y Villar Gordo $\mathrm{J}$ destacan el tamaño del referente (igual que el ya indicado Villarón); los medievales Villar de Teiadiellos, Villar de Teias y El Villar de la Piedra Forada (Libro de la montería), Villar de los Marmolejos, Villar de la Torre, Villar de Silos, Villar de Fornos (Repartimiento de Écija, de 1263; Sanz, 1976: 543-548), así como los documentados en fuentes actuales Villar del Cantarero 5 , Villar de la Plata J, Piedra del Villar H, describen la existencia in situ de vestigios (sin duda de interés arqueológico) de culturas anteriores; ${ }^{6}$ Villar Quemado $\mathrm{Gu}$, Te y Villar Viejo Gu señalan el estado deteriorado en que se encuentra el villar; y Villar

\footnotetext{
2 Para facilitar la localización geográfica de los nombres citados indico la provincia correspondiente mediante las siguientes abreviaturas: $\mathrm{Av}=$ Ávila, $\mathrm{Ba}=$ Badajoz, $\mathrm{Ca}=$ Cádiz, $\mathrm{Co}=$ Córdoba, $\mathrm{Gr}=$ Granada, $\mathrm{Gu}=$ Guadalajara, $\mathrm{H}=$ Huelva, $\mathrm{Hu}=$ Huesca, $\mathrm{J}=$ Jaén, Le $=$ León, $\mathrm{Ma}=$ Málaga, $\mathrm{Mu}=$ Murcia, $\mathrm{Na}=$ Navarra, $\mathrm{Se}=$ Sevilla, $\mathrm{Te}=$ Teruel, $\mathrm{To}=$ Toledo, $\mathrm{Z}=$ Zaragoza. En cuanto a los Estados mexicanos, las abreviaturas empleadas son: $\mathrm{Chh}=$ Chihuahua, $\mathrm{Chi}=$ Chiapas, $\mathrm{Coa}=$ Coahuila de Zaragoza, Gue $=$ Guerrero, Jal $=$ Jalisco, Qui $=$ Quintana Roo, Son $=$ Sonora, Tam $=$ Tamaulipas . ${ }^{3}$ Ilustran el valor colectivo de las formaciones toponímicas con-osa nombres morfológicamente análogos como La Lentiscosa 'lugar donde abunda el lentisco', El Pizarroso 'lugar donde hay pizarra'.

${ }^{4}$ Incluso en la toponimia mexicana existen nombres de este tipo: el buscador recoge $E l$ Villar (Coa-Jal-Son-Chh) y El Villarcito (Chi).

${ }^{5}$ En nombres de este tipo, la voz cantarero no designa un oficio, sino un lugar que se caracteriza por abundantes fragmentos de cántaros (-ero tiene, pues, valor colectivo; Gordón / Ruhstaller, 1991: 70).

${ }^{6}$ También el nombre toledano Villar del Moro hace referencia con toda seguridad a hallazgos de restos de antigua habitación, atribuidos por la población rural a un per-
} 
de las Culebras Se, Villarejo del Lobo J nos informan de que los moradores de los lugares designados no son seres humanos, sino animales salvajes ${ }^{7}$. No cabe la menor duda de que estos nombres hacen referencia no a poblaciones habitadas en el momento en que se produjo el bautismo del lugar, sino a los restos abandonados y ruinosos que quedaban de antiguos poblados. No debe extrañar el gran número de nombres de este tipo: en el momento en que se crearon estos topónimos (y la mayor parte de la toponimia castellana peninsular en general), esto es, en los años inmediatamente posteriores a la conquista cristiana de los territorios musulmanes, los hablantes que llevaron a cabo la retoponimización (en un primer momento los guerreros y, algo más tarde, los repobladores) se encontraron con numerosas poblaciones desiertas y destruidas a consecuencia del conflicto armado, lugares de los que ni siquiera llegaron a conocer su nombre tradicional ${ }^{8}$.

De hecho, son diversos los testimonios documentales que datan de la época de la repoblación en los que se emplea villar como nombre común en referencia a núcleos abandonados. Así, en la concesión, fechada en 1248, de un territorio en la actual provincia de Badajoz por parte Fernando III $^{9}$ se identifican los límites exponiendo:

...de parte de Badajoz por la Atalaya del Naharro, e dende como sale al villar que está en derecho de çafra, e dende como sale al mojón que dizen del Almendrera, e dende al azembuch que está encima de la sierra en derecho de la Fuente de la Figuera...

Y en el ya mencionado Repartimiento de Écija se citan como señales de demarcación diversos villares, concretamente en pasajes como "El Villar de la Torre, e en el otro villar que está aquende del monte", "Fezi-

sonaje fantástico de época anterior a la reconquista (véase Gordón / Ruhstaller, 1991: 120-126).

${ }^{7}$ El nombre El Villar de la Vieia, igualmente documentado en el Libro de la montería, podría hacer alusión a la creencia de que el lugar estaba habitado por la Vieja, ser mítico que se manifiesta en parajes solitarios y misteriosos.

${ }^{8}$ En cambio, los nombres de tradición árabe de las localidades que se mantenían intactas y en las que los cristianos se instalaron sustituyendo de forma inmediata a la población musulmana se incorporaron al castellano regional y generalmente se conservan hasta hoy.

${ }^{9}$ El texto se reproduce en el CORDE bajo el título "Carta por la que Fernando III concede un término a la orden de Santiago". 
mos aldea en Los Fontanales, do está un villar pequenno", "el villar de suso de Soto Gordo", "llegamos a un villar do está un pozo" o "vn villar que está de suso de vna penna redonda". Se trata sin lugar a dudas en todos estos casos de caseríos abandonados, a juzgar por el hecho de que no tengan nombre propio y sean mencionados en los deslindes como si se tratara de accidentes del terreno cualesquiera.

Esta conclusión de que villar realmente no significa 'población' o 'pueblo pequeño' (como define el diccionario académico), sino 'poblado anónimo, abandonado y ruinoso', que podemos extraer del análisis de los nombres de lugar, se confirma de forma rotunda a través de varios testimonios de la voz como apelativo en un autor de principios del s. XVII: el humanista Rodrigo Caro. En su Memorial de la villa de Utrera (1604), en el que describe detalladamente los hallazgos arqueológicos que había realizado en el municipio sevillano (Ruhstaller 1990: 115-119), da cuenta con admiración del gran número de núcleos abandonados en los que se conservaban todo tipo de vestigios de culturas antiguas. Así, en el capítulo titulado "De los villares que hay cerca de Utrera y del municipio Siario" informa:

Hay cerca de esta villa de Utrera y en sus cortijos y tierras de labor tantos villares y rastros de poblaciones antiguas, que ya que los libros y memorias de los hombres se hayan acabado para darnos razón y testimonio de que fueron, las mismas piedras mudas que el tiempo dejó por trofeos y señales de victoria nos muestran parte de lo que pretendemos, que es darnos a entender que donde ahora el diligente labrador anda solícito sembrando, allí mismo, sin delito, se borró la memoria de un lugar y habitación de hombres, quedando apenas de ella una confusa y lastimosa noticia.

Y en el capítulo dedicado a los "demás vestigios de antigüedad y villares" insiste:

En todo el término de Utrera, desde que salen de sus muros, es cosa maravillosa que no caminarán a parte alguna una legua que luego no se encuentren villares, unos pequeños y otros grandes. Yo solo haré mención de algunos que me han parecido más insignes. De este número es el cerro de la Cabeza de Alcázar o Faznalcázar, donde permanece una cueva, donde dicen haber estado la iglesia parroquial de este lugar, de un buen préstamo o beneficio; según lo cual, después que el rey D. Fernando ganó a Sevilla, debió ser lugar de cristianos; y el nombre da a 
entender haberlo poseído los árabes. Hay algunos paredones y infinitas piedras de edificios, aunque por ser cortijo y muy cultivado, los arados todo lo más han pervertido y deshecho.

En la iglesia de Santa María, desbaratando el altar mayor para reedificar la capilla, se hallaron puestas como material cinco tablas de mármol, que yo tengo ahora en mi casa, y sospecho se trujeron en tiempos passados de un villar que está de aquí una legua o poco más, que llaman Fazalcazar. [...] En casa del maestro Joan Jiménez Bernal se guarda una imagen pequeña de bronce, que se halló en un villar de nuestros campos...

El contexto en el que aparece villar en los párrafos reproducidos no deja lugar a dudas de que para Caro villar no significaba 'población', 'lugar habitado', sino específicamente 'población abandonada y en ruinas', a juzgar por el hecho de que nunca añada una especificación explícita, como un adjetivo del tipo [villar] viejo, antiguo, desierto o yer$m o^{10}$. No debe sorprendernos que la lengua antigua conociera una voz con el significado específico de 'localidad deshabitada y ruinosa', pues, como ya hemos visto, este tipo de realidad abundaba enormemente en la España medieval, muy especialmente en las regiones que acababan de ser reconquistadas, y ello no solo por los estragos que había causado la guerra, sino también por el déficit demográfico que se produjo a raíz de la expulsión de la población morisca: no había pobladores cristianos suficientes para ocupar y explotar el inmenso territorio ganado en muy poco tiempo, y la supervivencia de los recién llegados era todo menos fácil y segura, como han expuesto con detalle historiadores como Manuel González Jiménez (1980: 119 y ss.).

\footnotetext{
${ }^{10}$ Es cierto que en algún texto medieval sí aparece tal referencia explícita al estado de abandono en que se encontraba la población señalada. En el fallo de un pleito de Alfonso X dirigido a Castilla la Nueva de 1262 recogido en el CORDE leemos: “...e contra oriente de Alcocer en su derecho a la sierra de Lares e de la sierra de Lares en su derecho al villar antigo que esta en la ribera de Guadalemar e entre Guadalemar e Alcocer e del villar antigo en su derecho como passa en Guadalemar..."; y en una sentencia de 1281 se alude a un "villar yermo de Piedraffita con todo su eredamiento". Al tratarse de casos tan solo esporádicos (tres de un total de más de cuarenta testimonios medievales) no cabe duda de que estamos ante expresiones pleonásticas que intentan subrayar el carácter desierto de las poblaciones referidas.
} 
3. En la toponimia del área del castellano aparece con cierta recurrencia la forma Fuentidueña (con variante minoritaria Fuentedueña), como revelan los datos que he reunido:

Fuentidueña (topónimo mayor de la provincia de Segovia)

Fuentidueña de Tajo (topónimo mayor de la provincia de Madrid)

Arroyo de la Fuentedueña (Carabias, Guadalajara)

Calle de la Fuentidueña (Santa Cruz de la Zarza, Madrid)

Arroyo y Zahúrdas de Fuentidueña (La Palma del Condado, Huelva)

Fuentidueña o Fuentidueñas (Baena Jaén)

Cortijo y Loma de Fuentidueña (Écija, Sevilla)

Fuente Dueña (Villacarrillo, Jaén)

Fuente la Dueña (Beas de Segura, Jaén)

La antigüedad de estas formaciones queda demostrada por el hecho de que exista documentación escrita de este tipo toponímico que remonta al menos al siglo XII, y, por otra parte, por el de que dos de los nombres fueran topónimos mayores ya en época medieval. Concretamente, el nombre del término sevillano de Écija conocido hoy como Fuentidueña aparece dos veces en el Repartimiento, fechado en 1263, de dicha ciudad como Fuenteduenna ${ }^{11}$. El topónimo mayor segoviano, a su vez, se cita como Fuentidueña en varias transcripciones de un fuero concedido en el s. XII según G. Lafont Mateo, mientras que en la confirmación del texto legal, redactada en latín, otorgada por los Reyes Católicos, encontramos la versión latinizada "ffacta carta in Covos aldea de Fontidonia" (Lafont, 2010: 46). La misma forma latinizada es empleada también por Juan de Mariana ("Alvari Lunæ [...] fontidonice regulus"; Mariana, 1605: Index). El Itinerario de Hernando Colón contiene las variantes la barca de fuente dueña / la barca de fuentidueña y la barca de fuente y dueña (Rodríguez Toro, 2002: 34) ${ }^{12}$.

\footnotetext{
${ }^{11}$ El folio del documento que contiene las dos menciones del nombre puede consultarse en http://archivomunicipal.ecija.es/actividades/exposiciones_virtuales/historia_de_ecija/historia_de_ecija.html

${ }^{12}$ En cuanto al nombre Arroyo de Fuentidueña de La Palma del Condado no está claro si hace alusión a un referente presente en el lugar o si deriva de un antropónimo. A favor de la primera posibilidad aboga el hecho de que estemos ante un hidrónimo, a favor de la segunda el de que en la documentación local aparezca una familia Fontidueña (Molina 2008: 166-167).
} 
El topónimo ha sido objeto de diversas interpretaciones. La mayoría de ellas parten de la convicción de que la secuencia dueña corresponde a la voz homónima del castellano, dueña $<$ DOMINA $^{13}$. Esta es la opinión de Á. Llamazares (2001: 95), autor que afirma que

[e]n la Edad Media, "Domno" y "Domna" (< DOMINU, -A) no se usan solo como títulos de respeto y/o tratamiento, sino de santidad. Baste recordar que precisamente el monasterio de Sahagún, puesto bajo la advocación de los santos Facundo y Primitivo, recibía el nombre de Domnos Sanctos, Jesucristo aparece designado en la documentación medieval como "Domno Christo" y "Domno Salvatore"; es f[r]ecuente el topónimo Fuentidueña (> [sic] FONTE DOMINA), equivalente significativo de Fuensanta.

Según otra hipótesis, Fuentidueña realmente es Fuente de la Dueña; la "dueña" a la que alude supuestamente el nombre es Doña Urraca, es decir, la reina Urraca I de León, "que estuvo encerrada en la fortaleza y que bajaba a la fuente que estaba conectada con el castillo por una galería subterránea" (Hernando, Sánchez \& Torres, 2009: 322). Coincidente con esta interpretación al menos desde el punto de vista léxico, aunque no desde el referencial, es la de que la voz dueña se refiere a unas "señoras mayores de compañía" anónimas que acudían a la fuente en cuestión, o incluso a unas ninfas mencionadas nada menos que por Tito Livio ${ }^{14}$. Apoya al menos el aspecto léxico de esta explicación Rodríguez Toro (2002: 34), autor que justifica que se ha producido una "desaparición o fusión de la preposición de que sirve de 'relacionante' entre el apelativo y el nombre propio".

El principal punto débil de estas interpretaciones que ven en las dos últimas sílabas la voz dueña es precisamente la estructura morfosintáctica del nombre. Es cierto que la preposición y el artículo son elididos con frecuencia en nombres que integran dos sustantivos (Cerro del Pino $>$ Cerro Pino); no obstante, ni siquiera en la documentación más antigua del nombre que aquí nos interesa aparece rastro alguno de dichos "relacionantes". Esto sería esperable desde luego en el caso del nombre ecijano, que se atestigua ya en el repartimiento de 1263 , momento en

\footnotetext{
${ }^{13}$ Esta interpretación subyace también a las variantes gráficas Fuente Dueña, Fuente y Dueña o Fuente la Dueña que hemos señalado.

${ }^{14}$ Todas estas teorías se exponen en Hernando / Sánchez / Torres, 2009: 322.
} 
que el topónimo, de indudable origen castellano, acababa de crearse. Tampoco resulta convincente la explicación de dueño como sinónimo de santo; es cierto que en textos muy arcaicos la forma se emplea en hagiónimos como el mencionado Domno Salvatore, pero siempre antepuesto a un nombre propio y como fórmula fija. A estos insalvables obstáculos formales se suma la dificultad de justificar la motivación de un elemento dueña integrado en el nombre: dado que, como demuestra la documentación medieval, indudablemente se trata de un singular, ha de descartarse cualquier interpretación que relacione el nombre con un colectivo (como unas presuntas señoras mayores de compañía, o incluso ninfas ${ }^{15}$ ), y para vincular el lugar con un individuo concreto debería existir alguna prueba histórica.

Otro planteamiento muy distinto es el que propone Á. Galmés de Fuentes. Para el filólogo el elemento agregado a fuente es de origen celta; el étimo concreto que, retomando una idea de Albert Dauzat, postula es onna, que define como 'fuente' o 'arroyo' (Galmés de Fuentes, 1996: $24)^{16}$, comentando: "Fuentidueña (Segovia), tautología, tan frecuente en la toponimia, en este caso con el significado de 'fuente de la fuente",. Galmés, además, relaciona la forma con otros hidrónimos como Güeña (río de Asturias), Urueña (Valladolid), Piloña, Oñón (Asturias), Canto$\tilde{n} a$ (Orense), Oña (Burgos), Santoña (Santander), Oñate (Guipúzcoa), y también con los franceses Garonne, Marne o Saône (que habían sido el objeto de la teoría de Dauzat). El problema de esta hipótesis -además de que cualquier étimo que remonta a un estrato tan insuficientemente conocido como el celta ha de considerarse de antemano sumamente hipotético (y más, si no se parte de un sólido corpus de documentación antigua de todas las formas que se presentan como emparentadas)- es que no ofrece ninguna explicación de la secuencia -id-; evidentemente, no basta con interpretar sílabas o conjuntos de sílabas contenidas en una forma onomástica y hacer caso omiso del resto de la formación y sin ofrecer una explicación global de esta.

\footnotetext{
${ }^{15}$ Nombres que contienen el plural dueñas, como los andaluces Cortijo de las Dueñas (Paradas y Utrera), Las Dueñas (Osuna, La Carlota y Cortes de la Frontera), Prado de las Dueñas (Jerez de la Frontera) o Vegas de las Dueñas (Peñaflor), en cambio, identifican demostradamente antiguas propiedades de monasterios femeninos.

${ }^{16}$ En Galmés de Fuentes, 2000: 50 se repite la misma información. Recoge la teoría de Galmés Jordán Cólera, 2002: 227.
} 
Para explicar el nombre de un modo lingüísticamente convincente debemos partir de un análisis riguroso de las variantes con que se documenta. Como hemos visto, el nombre que se atestigua en 1263 en el Repartimiento de Écija como Fuenteduenna (y hoy se conoce como Fuentidueña) constituía en ese momento una creación toponímica muy reciente, prácticamente simultánea a la redacción del texto, por lo que cabe suponer que los hablantes aún eran conscientes del valor semántico inicial de la formación y de los recursos morfológicos en que esta se basaba ${ }^{17}$. Fuentidueña y Fuentedueña son, además, las formas con que generalmente aparecen documentados los topónimos mayores segoviano y madrileño; la explicación del nombre debe, pues, partir indudablemente de estas formas, mientras que todas las demás han de considerarse alteraciones posteriores ${ }^{18}$.

Dado que el nombre evidentemente se compone de dos elementos, y que el primero es el cast. fuente, el segundo debe contener una individualización de este tipo de referente. La terminación en $-a$ apunta a que se trata de un adjetivo, y a que estamos ante una formación paralela a las conocidas Fuen Santa, Fuen Bellida, Fuen Cubierta, Fuen Fría que se conservan en abundancia en la toponimia española, o a las formas Fuent Luenga, Fuent Quaiada, Fuent Calada que se documentan ya en textos medievales como el Libro de la montería (Ruhstaller, 1995: 107108). La característica específica de la fuente en cuestión sin duda fue su idoneidad para el aprovechamiento humano (frente a otros manantiales cuya agua no era potable, o ni siquiera aprovechable para usos ganaderos o agrícolas ${ }^{19}$ ). De hecho, el adjetivo lat. IDŌNEUS pudo adoptar perfectamente la forma idueño en castellano (Ruhstaller, 1992: 138); la diptongación de la $\overline{\mathrm{O}}$ en este contexto específico puede considerarse regular (cf. CICŌNIA > cigüeña, RISŌNEU > risueño, FAVŌNIU > arag. fagüeño; Menéndez Pidal, 1980: 65-66). No se trata, sin embargo,

\footnotetext{
${ }^{17}$ Es muy improbable que se trate de una forma precastellana, tanto por su aspecto y su recurrencia en la toponimia española, como por el hecho de que los nombres contenidos en el texto medieval ecijano sean en su inmensa mayoría innovaciones castellanas (en cambio, los nombres adoptados de la anterior población arabófona son muy escasos en el área, como ya vimos al estudiar la voz villar).

${ }^{18}$ Las variantes Fuente la Dueña o Fuentidueñas (al igual que la transcripción Fuente Dueña) reflejan que el nombre ha sido objeto de reinterpretaciones basadas en la voz dueña por parte de los hablantes.

${ }^{19}$ Estas otras fuentes reciben nombres como Fuente Mala $\mathrm{H}-\mathrm{Se}$, Fuente Amarga Ca-Gr, Fuente Agria Co, etc.
} 
de un elemento patrimonial del léxico castellano, sino de un semicultismo, como revela la llamativa alternancia entre idueño (la variante más cercana al modelo latino) y edueño (la variante completamente popularizada). La latinización Fontidonia (nunca *Fons Dominae ni nada similar) que encontramos en textos posteriores parece indicar que entre los cultos pervivía la conciencia acerca del significado que había tenido el nombre en el momento de su creación. No podemos ocultar que es poco habitual encontrar en toponimia un semicultismo no documentado como apelativo en textos escritos. La explicación lingüística, no obstante, es tan incuestionable tanto desde el punto de vista fonético como desde el semántico y motivacional que ha de admitirse que la toponimia en ocasiones es capaz de suministrar a la lexicología histórica datos totalmente indocumentados en función apelativa ${ }^{20}$; como caso comparable podría citarse el del adj. albo, contenido en topónimos como Villalba, Montalbo, Peñalba o Torralba (frente a la forma patrimonial obo, presente en Torroba o Montovo; cf. DCECH, s. v. albo).

4. Otro tipo toponímico que puede encontrarse con cierta frecuencia en el paisaje toponímico hispánico es el que se basa en la voz palanca: La Palanca Ca-J-H-Te-Tam, Palancas Molinero Te, Masía de la Palanca Te, Palanca Cascajar Te, Paso Palanca Te, Cabezo las Palancas $\mathrm{H}$, Cuerda de la Palanca Co, así como en México Las Palancas (Gue). Ocasionalmente aparecen también derivados de esta voz, como el masculino palanco (Camino del Palanco Na, El Palanco $\mathrm{Na}$ ) o el aumentativo palancón (El Palancón Gue); el derivado más frecuente, no obstante, es el colectivo palancar (Arroyo del Palancar Co-Ma-Gr, Río Palancar Co, Río Palancares Gr, Barranco del Palancar Al-Se, Garganta del Palancar Ca, El Palancar Ca-Co-Gu-J-Te-Qui, Arroyo de los Palancares Gr-J-Se). El mismo valor que palancar debe tener otro colectivo, palancada, que encontramos en la toponimia turolense (Alto de la Palancada Te). Nos ilustran la antigüedad de estos tipos toponímicos los nombres El Palancar (tres casos), El Palancar de Facinas, El Palancar de Gudumer, El Palancar de las Cuevas de Vieja, El Palancar de los Castelleios y La Senda del Palancar, documentados en el Libro de la montería (h. 1344), y Elcock (1961: 313) y Frago (1981: 41) señalaron para Aragón ejemplos aún más antiguos: "Et de collatu de

\footnotetext{
${ }^{20}$ Para otros casos similares véase Gordón, 1992, 1993a, 1993b, Ruhstaller, 1995.
} 
Fontanicas ad podium de la Palanga" (año 1087); "Ex illis uero decem pecis quas habemus in termino de Mosquera, primam earum uocatur peça de Palanca" (año 1237).

La consulta de los diccionarios de la lengua general no ayuda a esclarecer el significado exacto que subyace a estas formaciones toponímicas. El diccionario académico recoge las tres acepciones siguientes: 'barra inflexible, recta, angular o curva, que se apoya y puede girar sobre un punto, y sirve para transmitir una fuerza'; 'pértiga o palo de que se sirven los palanquines para llevar entre dos un gran peso'; y 'plataforma desde la que salta al agua el nadador'. Ya para los lexicógrafos antiguos, palanca era más que nada lo definido en la primera de estas acepciones: Nebrija explicó "palanca para sopalancar: palanga", mientras que Covarrubias definió palanca como 'barra de hierro para leuantar las piedras grandes'; más detalles técnicos ofrecía el Diccionario de autoridades:

PALANCA. s. f. Una de las máchinas fundamentales de la Machinária. Es una pértiga de hierro o madera, que sirve para levantar cosas de mucho peso. Hai tres géneros de palancas: la del primer género es aquella en que el hypomóchlio se halla entre el peso y la potencia: la del segundo aquella en que el peso está entre el hypomóchlio y la potencia: y la del tercero, la en que la potencia está entre el hypomochlio y el peso. Tosc. tom. 3. pl. 278. Latín. Vectis.

Es evidente que la única acepción que los diccionarios del español recogen de forma constante desde hace siglos, 'barra que sirve para transmitir una fuerza', no es capaz de explicar los referidos nombres de lugar desde el punto de vista motivacional, puesto que no se ofrece ninguna motivación plausible (es decir, un posible referente presente en el lugar designado). Sin embargo, las acepciones segunda y tercera del DRAE, así como un dato adicional que ya suministraba Covarrubias ("Tambien se dize Palanca la pertiga de los ganapanes: en la qual suelen lleuar entre dos vn gran peso: y estos se llaman Palanquines en Seuilla") ${ }^{21}$, revelan que palanca ha tenido otros valores afines, y que todos estos valores comparten la información semántica básica 'barra $\mathrm{o}$ palo que ha de soportar un gran peso'.

\footnotetext{
${ }^{21}$ No cabe duda de que la segunda acepción del diccionario académico tiene su origen en este comentario de Covarrubias.
} 
Ya el étimo latino de palanca era una voz polisémica, y sus acepciones eran similares a las de sus continuaciones romances. Los autores del DCECH (s.v. lancha I) atribuyen al lat. PHALANGA simultáneamente los valores 'rodillo', 'pértiga', 'palanca' y 'plancha o tablón para pasar una corriente de agua'; el más interesante para explicar topónimos es sin duda alguna el último, pues en las vías de comunicación antiguas era muy común el recurso a simples palos, tablas y troncos para salvar los cauces de los arroyos (Ruhstaller, 2014: 549). Este significado de la continuación romance palanca, en efecto, está bastante difundido en las hablas aragonesas: Elcock señala que en el Valle de Tena la voz vale 'pasarela', y Frago (1981: 41) la documenta con significado 'tablón o madero que sirve para atravesar un cauce' en la Ribera del Ebro. El mismo significado tuvo también la variante vulgar PLANCA de PHALANGA, definida en Festo como "plancas: tabulas planas", de la que proceden el fr. planche, el oc. planca y el piam. pianca 'tablón para pasar, pasadera', según informa el DCECH (s.v. lancha I); este diccionario añade (s.v. palanca) que también la voz catalana planca se usa como 'puentecillo'. En vista de todos estos datos no cabe duda alguna de que también el cast. palanca ha tenido en todo su territorio (y no solo el peninsular, como revelan los nombres mexicanos citados) y desde los orígenes del idioma el significado 'pasarela, tablón para cruzar una corriente de agua', a pesar de que en la lengua actual la voz conserva uso casi exclusivamente en el sentido de 'barra inflexible que se apoya y puede girar sobre un punto, y sirve para transmitir una fuerza'.

5. La voz rinconada es definida por el diccionario académico como 'ángulo entrante que se forma en la unión de dos casas, calles o caminos, o entre dos montes'. Esta definición conserva básicamente la información recogida ya en el Diccionario de autoridades, si bien añade una puntualización: si en el primer diccionario de la Corporación la voz se explicaba como 'el rincón que se forma de dos casas, calles o camínos', la edición actualmente vigente añade, perpetuando una especificación introducida en 1803, que se aplica también a un rincón formado por dos montes. El examen de los nombres de lugar basados en la voz rincona$d a$ y de los lugares que designan muestra que, en efecto, en muchos casos se trata de terrenos encerrados entre montes o entre caminos. A los accidentes que delimitan los terrenos nombrados, no obstante, debemos añadir el de las corrientes fluviales, pues son muchos los casos en que 
las rinconadas toponímicas son terrenos delimitados por meandros de ríos: este es el caso de los nombres jiennenses Cortijo de la Rinconada (Sabiote) y La Rinconada (Chiclana de Segura), que designan terrenos encerrados en recodos del Guadalimar, o Cortijo de la Rinconada Alta (municipio de Córdoba) y La Rinconada (localidad de la provincia de Sevilla), que describen la ubicación de los lugares en cuestión en el interior de dos grandes meandros que forma el Guadalquivir. El historiador Julio González creyó poder identificar con la localidad sevillana que acabo de mencionar una referencia contenida en un pasaje del $\mathrm{Li}$ bro del repartimiento de Sevilla (González, 1951: 265), a juzgar por la mayúscula con que transcribió la voz renconada; no obstante, la lectura atenta del pasaje y la localización del lugar señalado en los mapas actuales revela que renconada se emplea en el texto como apelativo que describe un lugar que en 1253 aún no tenía nombre para los hablantes de castellano, situado a varios kilómetros río arriba (Ruhstaller, 1992: 240, n. 1): "Esta es la heredat del pan de los ricos omes: [...] A Ruy Lopes de Mendoça, XV yugadas en Guadaxox, en la renconada que entra en Guadalquivir allende el río de Guadaxox".

Este valor específico 'terreno encerrado en el meandro de un río', no recogido, como hemos dicho, en los diccionarios, curiosamente es el mejor documentado en época temprana, pues al testimonio sevillano que acabo de citar se suman uno contemporáneo de Murcia $^{22}$ y otro algo más tardío de Jerez de la Frontera ${ }^{23}$, e incluso parece reflejarlo la atestiguación más antigua conocida en el idioma, la de la Vida de Santo Domingo de Silos (c. 1236) de Berceo (texto recogido en el CORDE):

Contra tierras de Lara, faz a una contrada, en río de Arlança, en una renconada, iaze un monesterio, una casa onrada, San Pedro de Arlança es por nombre clamada.

6. Los casos que he presentado en lo anterior constituyen ejemplos representativos de cómo la investigación toponomástica permite conocer

\footnotetext{
${ }^{22}$ Se trata del siguiente pasaje del Repartimiento de Murcia incluido en el CORDE: "Las otras iii ataffullas por alffaba et media a el mismo, cabo del rio, sobre la puente de los moros en la Alquibla, vna renconada que dexa el rio cabo la carrera."

${ }^{23}$ En un deslinde de este término gaditano del año 1274 se habla de "dos rinconadas que se facen del río Guadalet" (Ruhstaller 1992: 240).
} 
todo tipo de aspectos de la historia del léxico de los que no nos han llegado testimonios a través de otras fuentes documentales. En primer lugar, los materiales toponímicos a menudo ayudan a esclarecer pormenores cronológicos de la trayectoria histórica de las palabras, como demuestran las primeras atestiguaciones escritas en el idioma que he señalado para formas como idueño, palanca o palancar. En segundo lugar, he llamado la atención sobre formaciones como villarejillo, villarón, villarosa, palanco, palancada, palancar o palancón, que constituyen derivados no recogidos en las obras lexicográficas. En tercer lugar, he puntualizado el valor semántico de voces como villar ('población abandonada y ruinosa'), rinconada ('terreno encerrado por el meandro de un río'), palanca ('pasarela de tablas'), palancar ('íd.'). En cuarto lugar, he ofrecido datos que ayudan a conocer con mayor precisión la difusión geográfica alcanzada por ciertas voces (palanca y palancar en el sentido 'pasarela' no solo existen en aragonés, sino en el español de toda la Península e incluso en México; el semicultismo idueño / var. edueño $<$ IDŌNEUS ha tenido cierta vitalidad desde Segovia, pasando por Madrid y Guadalajara, hasta Andalucía, al menos hasta el s. XIII). El ejemplo de la última voz citada incluso muestra cómo ocasionalmente la toponimia ofrece el único testimonio de la existencia de una palabra en el idioma.

Esta corta serie de ejemplos, que sin dificultad podría ampliarse a partir de otros materiales estudiados en los trabajos sobre toponimia, ilustra de forma contundente la gran utilidad que esta rama de la lingüística puede tener para la investigación histórica del léxico español. Para aprovechar todo el potencial de esta fuente complementaria de información, no obstante, sería importante promover la elaboración sistemática de nuevos estudios sobre toponimia hispánica; lo ideal sería que estos estudios se integrasen en el marco de un proyecto de amplias dimensiones, basado en un sólido aparato documental, así como en una metodología rigurosa y coherente cuya prioridad no fuese tanto la interpretación de cada nombre como hecho individual y de interés local, sino su explicación como fenómeno léxico-semántico y dialectológico, es decir, como formaciones (fosilizadas hasta cierto punto, como es obvio) que reflejan el uso, en un área geolingüística determinada y en una época de la historia de la lengua, del léxico vivo a partir del cual fueron creados. Finalmente, sería necesario que también los expertos en lexicología histórica y etimología no especializados en onomástica tomaran 
conciencia del valor de esta fuente de información, y la integraran de modo sistemático en sus investigaciones.

\section{Bibliografía}

Fuentes de material toponímico

Ariño Rico, L. 1980. Repertorio de nombres geográficos. Huesca. Zaragoza: Anubar.

Callado García, A. 1974. Repertorio de nombres geográficos. Zaragoza. Valencia: Anubar.

Centro de Información Territorial de Aragón. Nomenclátor Geográfico de Aragón. http://idearagon.aragon.es/toponimia

Cervero Pozo, V. 1975. Repertorio de nombres geográficos. Toledo. Valencia: Anubar.

González Velasco, C. 1981. Repertorio de nombres geográficos. Segovia. Zaragoza: Anubar.

López Azorín, V. 1979. Repertorio de nombres geográficos. Badajoz. Zaragoza: Anubar.

López Navarro, M. A. 1979. Repertorio de nombres geográficos. Ávila. Zaragoza: Anubar.

Instituto Nacional de Estadística y Geografía de México. Sistema de consulta de nombres geográficos. http://www.inegi.org.mx/geo/contenidos/ nomgeo/default.aspx [Acceso enero de 2015].

Instituto Navarro del Vascuence. Toponimia Oficial de Navarra. Base de datos. $\mathrm{http}: / /$ toponimianavarra.tracasa.es [Acceso enero de 2015].

Junta de Andalucía. 1990. Inventario de toponimia andaluza. Sevilla (9 vol.).

Junta de Andalucía. Buscador de nombres geográficos. http://www.ideandalucia.es/nomenclator [Acceso enero de 2015].

Muñoz Garrido, V. 1974. Repertorio de nombres geográficos. Teruel. Valencia: Anubar.

Muñoz Pomer, M. R. 1974. Repertorio de nombres geográficos. Jaén. Valencia: Anubar.

Noblejas Pérez, M. P. 1979. Repertorio de nombres geográficos. Huelva. Zaragoza: Anubar.

Pacheco Moya, C. I. 1983. Repertorio de nombres geográficos. Córdoba. Zaragoza: Anubar.

Vallcanera Calatayud, M. J. 1976. Repertorio de nombres geográficos. Murcia. Valencia: Anubar.

Yago Andrés, M. C. 1974. Repertorio de nombres geográficos. Guadalajara. Valencia: Anubar. 
Estudios:

Caro, R. 1604. Memorial de la villa de Utrera. Copiado del códice que está en la librería del Convento del Carmen de Utrera. Sevilla, 1883. http:// www.forgottenbooks.com/.../Memorial_de_la_Villa_de_Utrera

Corominas, J. \& Pascual, J. A. 1980-1991. Diccionario crítico etimológico castellano e hispánico. Madrid: Gredos (6 vol.) (cit. como DCECH).

Elcock, W. D. 1961. Toponimia del valle de Tena. Archivo de Filología Aragonesa 12-13: 299-320.

Frago Gracia, J. A. 1981. Toponimia navarroaragonesa del Ebro III. Vías de comunicación. Archivo de Filología Aragonesa 28-29: 31-56.

Galmés de Fuentes, Á. 1996. Toponimia: mito e historia. Madrid: Real Academia de la Historia.

Galmés de Fuentes, Á. 2000. Los topónimos: sus blasones y trofeos (la toponimia mítica). Madrid: Real Academia de la Historia.

González, J. 1951. Repartimiento de Sevilla II. Madrid: C.S.I.C.

González Jiménez, M. 1980. En torno a los orígenes de Andalucía. La repoblación del siglo XIII. Sevilla: Universidad de Sevilla.

Gordón Peral, M. D. 1992. Nuevas aportaciones a la lexicología hispánica. Derivados del lat. vg. FICTUS en castellano y mozárabe. Vox Romanica 51: 211-219.

Gordón Peral, M. D. 1993a. Acerca de la raíz *MUKORNO- y sus derivados en la Península Ibérica: nota crítica al DECH. Zeitschrift für romanische Philologie 109, 1-2: 84-95.

Gordón Peral, M. D. 1993b. Arcaísmos léxicos presentes en la oronimia hispánica. Zeitschrift für romanische Philologie 109, 1-2: 96-112.

Gordón Peral, M. D. \& Ruhstaller, S. 1991. Estudio léxico-semántico de los nombres de lugar onubenses. Toponimia y Arqueología. Sevilla: Alfar Universidad.

Gordón Peral, M. D. 2014. De toponimia e historia. La referencia a litigios sobre demarcaciones territoriales en la onomástica de lugares hispánicos. Rivista Italiana di Onomastica XX-1: 27-48.

Gordón Peral, M. D. 2015. Presencia italiana en la España meridional según el testimonio de la toponimia. Quaderni Internazionali di RION 5: 147170.

Jordán Cólera, C. 2002. De las Oestrymnides, la Garvmna e hidrotopónimos relacionados. Emérita LXX: 213-230.

Lafont Mateo, G. 2010. Pampliega, Torrepadierne y Santiuste. Mil años de Historia. Siglos VII al XVII. Salamanca.

Llamazares Sanjuán, Á. 2001. "MADRE” y topónimos afines en la mitad norte Peninsular. Lletres asturianes 79: 85-93. 
Mariana, J. de 1605. Historiae de rebus Hispaniae. Libri XXX. Toledo.

Menéndez Pidal, R. 1980. Manual de gramática histórica española (16. ${ }^{\mathrm{a}}$ ed.). Madrid.

Molina Díaz, F. 2008. El léxico de la tierra. Estudio toponomástico de los términos municipales de Bollullos Par del Condado y La Palma del Condado Huelva. Huelva: Diputación de Huelva.

Real Academia Española 1726-1739. Diccionario de la lengua castellana, en que se explica el verdadero sentido de las voces, su naturaleza y calidad, con las phrases o modos de hablar, los proverbios o refranes, $y$ otras cosas convenientes al uso de la lengua. Madrid. http://www.rae. es/recursos/diccionarios/diccionarios-anteriores-1726-1996/diccionario-de-autoridades\#sthash.7LMEkgha.dpuf

Real Academia Española 2014. Diccionario de la lengua española (23. ${ }^{\text {a ed.). }}$ Madrid, Gredos.

Real Academia Española. Banco de datos (CORDE) [en línea]. Corpus diacrónico del español. http://www.rae.es [Acceso enero de 2015].

Rodríguez Toro, J. J. 2002. Descripción y cosmografia de España (o Itinerario) de Hernando Colón. Estudio lingüístico. Sevilla: Universidad de Sevilla.

Rohlfs, G. 1951. Aspectos de toponimia española. Boletim de Filologia XII: 264-275.

Ruhstaller, S. 1990. Toponimia de la Campiña de Utrera. Sevilla: Fundación Luis Cernuda.

Ruhstaller, S. 1992. Toponimia de la región de Carmona. Bern: Francke.

Ruhstaller, S. 1995. Materiales para la lexicología histórica. Estudio y repertorio alfabético de las formas léxicas toponímicas contenidas en el Libro de la Montería de Alfonso XI. Tübingen: Max Niemeyer Verlag.

Ruhstaller, S. 2000. Las autoridades del Diccionario de autoridades. En Ruhstaller, S. \& Prado Aragonés, J. (ed.) Tendencias en la investigación lexicográfica del español. Huelva: Universidad de Huelva, 193-225.

Ruhstaller, S. 2010. Toponimia y geografía lingüística medieval. En Sousa Fernández, X. (ed.) Toponimia e cartografía. Santiago de Compostela: Consello da Cultura Galega-Instituto de la Lingua Galega, 129-146.

Ruhstaller, S. 2014. Motivación inicial y génesis de nombres. La toponimia creada por el colectivo de los caminantes. Rivista Italiana di Onomastica XX-2: 535-566.

Ruhstaller, S. \& Gordón, M. D. 1993. La toponimia como fuente de materiales para el diccionario etimológico hispánico. En G. Hilty (ed.) Actes du $X X^{e}$ Congrès International de Linguistique et Philologie Romanes, $\mathrm{t}$. VII. Berna: Francke, 733-745. 
Sanz Fuentes, M. J. 1976. Repartimiento de Écija. Historia. Instituciones. Documentos 3: 533-551.

Sanz Hernando, A.; Sánchez Álvarez, I. \& Torres Solana, V. 2009. Fuentidueña de Tajo. En Arquitectura y Desarrollo Urbano: Comunidad de Madrid. Madrid: Colegio Oficial de Arquitectos de Madrid, 314-398. http://oa.upm.es/22557/2/TomoXVI_Fuentiduena_2.pdf 
